\title{
Epidermal Growth Factor-PEG Functionalized PAMAM-Pentaethylenehexamine Dendron for Targeted Gene Delivery Produced by Click Chemistry
}

\author{
Haijun Yu, ${ }^{*, l,+}$ Yu Nie, ${ }^{\|,+}$Christian Dohmen," Yunqiu Li, ${ }^{\|, \S}$ and Ernst Wagner" \\ "Pharmaceutical Biotechnology, Center of Drug Research, Department of Pharmacy, and Center for Nanoscience (CeNS), \\ Ludwig-Maximilians Universität, Butenandtstrasse 5-13, D-81377 Munich, Germany
}

Supporting Information

ABSTRACT: Aim of this study was the site-specific conjugation of an epidermal growth factor (EGF)-polyethylene glycol (PEG) chain by click chemistry onto a poly(amido amine) (PAMAM) dendron, as a key step toward defined multifunctional carriers for targeted gene delivery. For this purpose, at first propargyl amine cored PAMAM dendrons with ester ends were synthesized. The chain terminal ester groups were then modified by oligoamines with different secondary amino densities. The oligoamine-modified PAMAM dendrons were well biocompatible, as demonstrated in cytotoxicity assays. Among the different oligoamine-modified dendrons, PAMAM-pentaethylenehexamine (PEHA) dendron polyplexes displayed the best gene transfer ability. Conjugation of PAMAM-PEHA dendron with PEG spacer was conducted via click reaction, which was performed before amidation with PEHA. The resultant PEG-PAMAM-PEHA copolymer was then coupled with EGF ligand. pDNA transfections in HuH-7 hepatocellular carcinoma cells showed a 10-fold higher efficiency with the polyplexes containing conjugated EGF as compared to the ligand-free ones, demonstrating the concept of ligand targeting. Overall gene transfer efficiencies, however, were moderate, suggesting that additional measures for overcoming subsequent intracellular bottlenecks in delivery have to be taken.

\section{INTRODUCTION}

Up to date, cationic lipids or polycations are widely investigated nonviral gene vectors. ${ }^{1-4}$ They form lipoplexes or polyplexes with negatively charged plasmid DNA (pDNA), antisense oligonucleotides (AONs), double stranded RNA (dsRNA) or small interfering RNA (siRNA). ${ }^{5-8}$ PAMAM dendrimers are special among the polycationic gene vectors. ${ }^{9-12}$ The primary amino groups on PAMAM dendrimer chain termini bind and compress pDNA into polyplexes. The tertiary amino groups in PAMAM dendrimer core supply PAMAM dendrimers with "proton sponge" capacity, which facilitate the endosome escape of PAMAM polyplexes. ${ }^{13-19}$ PAMAM dendrimers in higher generations cause more cytotoxicity than the low-generation ones, while the former produce higher transfection yields. ${ }^{20,21}$ To exploit the full potential of PAMAM dendrimer as gene carriers, it is crucial to develop novel PAMAM dendrimers with high gene transfer ability but low cytotoxicity. In our recent studies, oligoamines with different nitrogen densities were applied for oligoethylenimine (OEI) or poly(propylene imine) (PPI) dendrimer modification, a positive correlation between oligoamine chain length and transfection efficiency was found. This was attributed to the increased proton sponge effects of oligo (ethylene amines) with higher chain lengths. ${ }^{38,45}$

For gene delivery in vivo, the polyplexes are usually destabilized by serum protein absorption induced aggregation and physiological salt-triggered dissociation. ${ }^{22}$ PEG modification

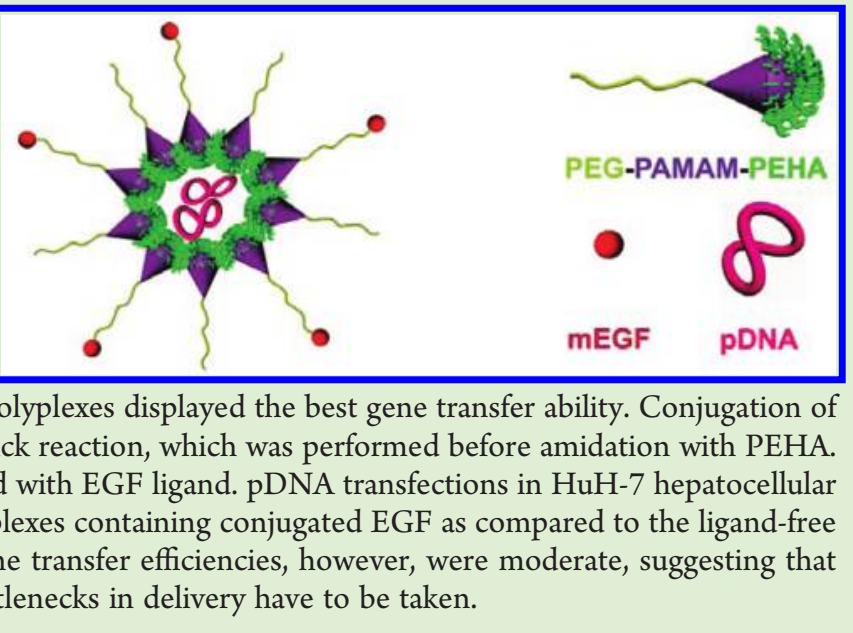

minimizes these disadvantages and elongates the circulation retention time of polyplexes. ${ }^{23,24}$ On the other hand, PEG shielding suppresses transfection efficiency by reducing intracellular uptake and endosome escape of polyplexes. ${ }^{25,26}$ Targeting ligands such as serum protein transferrin, antibodies, or growth factors have been incorporated into polyplexes to obtain higher targeted cell specificity and recovery the depressed transfection efficacy by PEG shielding. ${ }^{27-29}$ The epidermal growth factor receptor (EGFR) is highly expressed in a wide variety of human tumors, such as lung, breast and hepatocellular cancers. ${ }^{30}$ The binding of EGF to EGFR triggers the fast internalization of EGF conjugated polyplexes. ${ }^{31}$ Our previous studies demonstrated that the EGF-PEG conjugated polyethylenimine (EGF-PEG-PEI) polyplexes delivered pDNA or dsRNA into targeted cells or tumor xenograft much more efficiently than EGF free ones. ${ }^{32-36}$

With the knowledge from oligoamine-modified OEI/PPI vectors and EGF conjugated PEI polyplexes, we hypothesized that the transfection efficiency of low generation PAMAM dendrimers can be enhanced by introducing oligoamines and EGF moiety into their chain termini. In the present communication, we describe the synthesis of an EGF-PEG functionalized PAMAM linear-dendritic architectural copolymer. The PEG-PAMAM

Received: December 4, 2010

Revised: April 11, 2011

Published: April 14, 2011 
copolymer was prepared by site-specifically conjugating PEG chain onto PAMAM dendron via click chemistry. After terminal modification of PAMAM dendron with PEHA, the resultant PEG-PAMAM-PEHA copolymer was coupled with EGF ligand. The gene transfer study in $\mathrm{HuH}-7$ cells showed that EGF conjugated polyplexes were 10-fold more efficient than the EGF free ones. To our knowledge, this is the first report to produce ligand functionalized PEG-PAMAM linear-dendritic architectural copolymer via click chemistry. The methodology developed in this study could be easily applied for site-specific conjugation of different ligands with PAMAM dendrimers.

\section{MATERIALS AND METHODS}

Propargyl amine, 1-chloro-3-aminopropane hydrochloride, methyl acrylate, toluene, methanol (HPLC grade), deuterium oxide, $d$-chloroform, copper powder, copper bromide $(\mathrm{CuBr})$, pentamethyldiethylenetriamine (PMDETA), branched polyethylenimine $25 \mathrm{kDa}$ (BPEI), 2,5diphenyl-3-(4,5-dimethyl-2-thiazolyl) tetrazolium bromide (MTT), and oligoamines (ethylenediamine EDA, diethylenetriamine DEA, triethylenetetramine TETA, tetraethylenepentamine TEPA, pentaethylenehexamine PEHA) were obtained from Sigma-Aldrich (Munich, Germany). Linear PEI $22 \mathrm{kDa}$ (LPEI) was synthesized as described in our recently published work. ${ }^{36}$ PDP-PEG-NHS (ortho-pyridyldisulfide-PEG- $N$-hydroxyl-succinimide, $\left.M_{\mathrm{n}} 2 \mathrm{kDa}\right)$ and methyl-PEG-NHS $\left(M_{\mathrm{n}} 2 \mathrm{kDa}\right)$ were obtained from Shearwater Polymers (Huntsville, AL, U.S.A.). Mouse epidermal growth factor (mEGF) was purchased from Serotec (Oxford, England). mEGFPDP was prepared by following the method described in elsewhere. ${ }^{33,36}$ Regenerated cellulose dialysis tubing with different molecular weight cutoffs (MWCO) were obtained from Spectrum Medical Industries, Inc. (California, U.S.A.). Cell culture medium, antibiotics, and fetal calf serum (FCS) were purchased from Life Technologies (Karlsruhe, Germany). Cell culture lysis buffer and D-luciferin sodium salt were obtained from Promega (Mannheim, Germany). Plasmid DNA (Photinus pyralis luciferase under control of the CMV enhancer/promoter, described by Plank et al. ${ }^{37}$ ) was purified with the EndoFree Plasmid Kit from Qiagen (Hilden, Germany). Water was used as Millipore water (MQ). All other reagents were analytical grade and used without further treatment.

${ }^{1} \mathrm{H}$ and ${ }^{13} \mathrm{C}$ NMR spectra were recorded on an Eclipse 500 spectrometer at 500 and $125 \mathrm{MHz}$, respectively (JEOL, Tokyo, Japan). Mass spectra were recorded by fast atom bombardment mass spectra (FABMS, Finnigan, CA, USA) or electrospray-ionization mass spectra (ESIMS, Waters Micromass Technologies, Manchester, U.K.). The copolymer molecular weights $\left(M_{\mathrm{w}}, M_{\mathrm{n}}\right)$ and their corresponding polydispersity indexes (PDI, $M_{\mathrm{w}} / M_{\mathrm{n}}$ ) were determined by a GPC system (Agilent Technologies, Waldbronn, Germany), which was equipped with multidetectors (refractive index, UV and viscosity detectors), a NOVEMA $10 \mathrm{~mm}$ precolumn, and a NOVEMA 300 analytical column (PSS, Mainz, Germany). An acidic mobile phase was applied for GPC measurement $(0.1 \mathrm{v} / \mathrm{v} \% \mathrm{HCOOH}$ and $0.1 \mathrm{M} \mathrm{NaCl}$ in $\mathrm{MQ}, \mathrm{pH} 2.8)$. The chromatography was performed at a flow rate of $1.0 \mathrm{~mL} \cdot \mathrm{min}^{-1}$. Pullulans with different molecular weights were used as standard samples. ${ }^{38}$

Preparation of Propargyl-PAMAM Dendrons. In this study, propargyl-PAMAM dendrons were synthesized according to the procedure reported by Lee and Dong et al. ${ }^{39,40}$ The experimental details were shown in Supporting Information. The chemical structure of propargylPAMAM dendron G3.5 was confirmed by ${ }^{1} \mathrm{H}$ NMR spectra and mass spectra. ${ }^{1} \mathrm{H}$ NMR $\left(\mathrm{CDCl}_{3}\right): \delta=2.14(\mathrm{~s}, 1 \mathrm{H}), 2.32-2.42(\mathrm{~m}, 60 \mathrm{H})$, $2.50-2.54(\mathrm{~m}, 28 \mathrm{H}), 2.70-2.82(\mathrm{~m}, 60 \mathrm{H}), 3.20-3.24$ (br m, $28 \mathrm{H}), 3.44$ (s, 2H), 3.65 (s, 48H), 7.08 (br s, 8H), 7.65 (br s, 4H), 7.78 (br s, 2H). MS (ESI) $\mathrm{C}_{137} \mathrm{H}_{241} \mathrm{~N}_{29} \mathrm{O}_{46}$ : calcd, 3028.74; found, $1515.88[\mathrm{M} / 2+2 \mathrm{H}]$.

Terminal Modification of Propargyl PAMAM Dendron G4.0. The chain termini of PAMAM dendron G3.5 were modified by different oligoamines including EDA, DETA, TETA, TEPA, and PEHA.
Typically, $100 \mathrm{mg}$ ( $0.033 \mathrm{mmol})$ of PAMAM dendron G3.5 was dissolved in $10 \mathrm{~mL}$ of anhydrous methanol. The resultant dendron methanol solution was added dropwise into $50 \mathrm{~mL}$ of oligoamine methanol solution at oligoamine to ester group molar ratio of 50 . The amidation reaction was continued for three days at room temperature. Afterward, the reactant was purified by dialysis (MWCO $1.0 \mathrm{kDa}$ ) against MQ water and lyophilized to obtain the final product. The yield was around $70 \%$.

Synthesis of PDP-PEG- $\mathrm{N}_{3}$. The 1-azido-3-aminopropane monomer was prepared according to the literature method. ${ }^{41}{ }^{1} \mathrm{H} \mathrm{NMR}$ $\left(\mathrm{CDCl}_{3}\right): \delta=1.17($ br s, $2 \mathrm{H}), 1.72(\mathrm{q}, 2 \mathrm{H}) 2.78(\mathrm{t}, 2 \mathrm{H}), 3.35$ $(\mathrm{t}, 2 \mathrm{H}) \cdot{ }^{13} \mathrm{C} \mathrm{NMR}\left(\mathrm{CDCl}_{3}\right): \delta=32.31(\mathrm{~s}), 39.22(\mathrm{~s})$ and $49.06(\mathrm{~s})$. MS $\left(\mathrm{FAB}^{+}\right) \mathrm{C}_{3} \mathrm{H}_{8} \mathrm{~N}_{4}$ : calcd, 100.12; found, $101.14\left(\mathrm{M}^{+}+\mathrm{H}\right)$.

To synthesize PDP-PEG-N 3 , a certain amount of PDP-PEG2k-NHS solid (44 mg, $0.022 \mathrm{mmol}$ ) and 1-azido-3-aminopropane ( $88 \mathrm{mg}, 0.88 \mathrm{mmol}$ ) were dissolved in $1.0 \mathrm{~mL}$ of anhydrous DMF and reacted for 2 days at room temperature. Thereafter, the reactant was precipitated by cold diethyl ether and vacuum-dried to obtain target product of PDP-PEG$\mathrm{N}_{3}$ (33 mg, yield 77\%). ${ }^{1} \mathrm{H}$ NMR $\left(\mathrm{D}_{2} \mathrm{O}\right): \delta=1.75(\mathrm{~m}, 2 \mathrm{H}), 2.48-2.50$ $(\mathrm{m}, 4 \mathrm{H}), 2.60(\mathrm{t}, 2 \mathrm{H}), 2.96(\mathrm{t}, 2 \mathrm{H}), 3.05(\mathrm{t}, 2 \mathrm{H}), 3.27-3.32(\mathrm{~m}, 2 \mathrm{H})$, $3.44(\mathrm{~m}, 2 \mathrm{H}), 3.63(\mathrm{~s}, 182), 7.30(\mathrm{t}, 1 \mathrm{H}), 7.80(\mathrm{~m}, 2 \mathrm{H}), 8.35(\mathrm{t}, 1 \mathrm{H})$. FT-IR (ATR) $2850\left(\mathrm{v}_{\mathrm{CH}_{2}}\right), 2095\left(\mathrm{v}_{\mathrm{N}_{3}}\right), 1100 \mathrm{~cm}^{-1}\left(\mathrm{v}_{\mathrm{C}-\mathrm{O}}\right)$.

Synthesis of PDP-PEG-PAMAM $\left(\mathrm{G}_{4}\right)$-PEHA Conjugate via Click Chemistry. The PDP-PEG-PAMAM-PEHA conjugate was prepared by a two-step reaction. Defined amounts of PDP-PEG2k-azide ( $25 \mathrm{mg}, 0.013 \mathrm{~mol}$ ) and PAMAM dendron G3.5 (35 mg, $0.012 \mathrm{~mol}$ ) were dissolved in $2.0 \mathrm{~mL}$ of anhydrous ethanol with $\mathrm{CuBr}(1.8 \mathrm{mg}, 0.013$ $\mathrm{mol}$ ) and PMDETA (2.2 mg, $0.013 \mathrm{~mol})$ addition. The mixture was stirred for $12 \mathrm{~h}$ at $40^{\circ} \mathrm{C}$ water bath. After addition of certain amount of copper powder, the reaction was continued for additional $12 \mathrm{~h}$.

The ester groups on the PEG-PAMAM dendron were further aminolyzed by PEHA according to the procedure described above. The excess PEHA was removed by dialysis against MQ water overnight (MWCO $3.0 \mathrm{kDa}$ ). The free PDP-PEG2k-azide was removed by high performance liquid chromatography (HPLC) on an Äkta Basic system equipped with a cationic exchange column (Pharmacia Biotech, Uppsala, Sweden). The void fractions containing PDP-PEG-PAMAM-PEHA conjugate were pooled and purified by dialyzing against MQ water and subsequent lyophilization ( $33 \mathrm{mg}$, yield 60\%). To shield the positive charge on the polyplex surface, a PDP-free PEG2k-PAMAM-PEHA analog was synthesized as described above.

Preparation of EGF-PEG Functionalized PAMAM-PEHA Conjugate. The pyridyldisulfide group in the PDP-PEG2k-PAMAMPEHA conjugate was reduced with 50 molar equiv of DTT in $20 \mathrm{mM}$ Hepes buffer ( $\mathrm{pH}$ 7.4). The resultant HS-PEG-PAMAM-PEHA conjugate was purified by HPLC equipped with a G-25 superfine column (Sephadex G25 superfine, Amersham Biosciences, U.S.A.) equilibrated in $20 \mathrm{mM}$ Hepes buffer ( $\mathrm{pH}$ 7.4) under argon protection. The copolymer and sulfhydryl group concentrations in the collected solution were quantified by 2,4,6-trinitrobenzenesulfonic acid (TNBS) assay and Ellman's test with PAMAM-PEHA and cysteine controls, respectively. EGF-PEGPAMAM-PEHA conjugate was synthesized by following a protocol described elsewhere. ${ }^{33,36}$ In brief, $200 \mu \mathrm{L}$ of HS-PEG-PAMAM-PEHA Hepes solution $(0.061 \mu \mathrm{mol}$ of free sulfhydryl group) was mixed with 1.5 -fold excess of mEGF-PDP $(0.62 \mathrm{mg}, 0.10 \mu \mathrm{mol}$ in $1.0 \mathrm{~mL}$ of $30 \%$ ethanol-Hepes buffer, $\mathrm{pH}$ 7.4) at room temperature. The reaction was continued for $24 \mathrm{~h}$ under argon protection, and then the reaction mixture was directly loaded on a cationic exchange column to remove free mEGF moiety. After dialysis against $1 \mathrm{mM}$ Hepes buffer ( $\mathrm{pH} 7.4)$ (MWCO 1.0 kDa) overnight, the solution was concentrated by speed evaporator at room temperature. The polymer concentration was determined by TNBS assay.

Polyplex Preparation. pDNA-loaded polyplexes were prepared by adding the polymer solution to pDNA solution at indicated polycation to pDNA weight ratios ( $\mathrm{c} / \mathrm{p}$ ratios). Polyplexes were allowed to incubate for at least $20 \mathrm{~min}$ at room temperature prior to use. HBG 


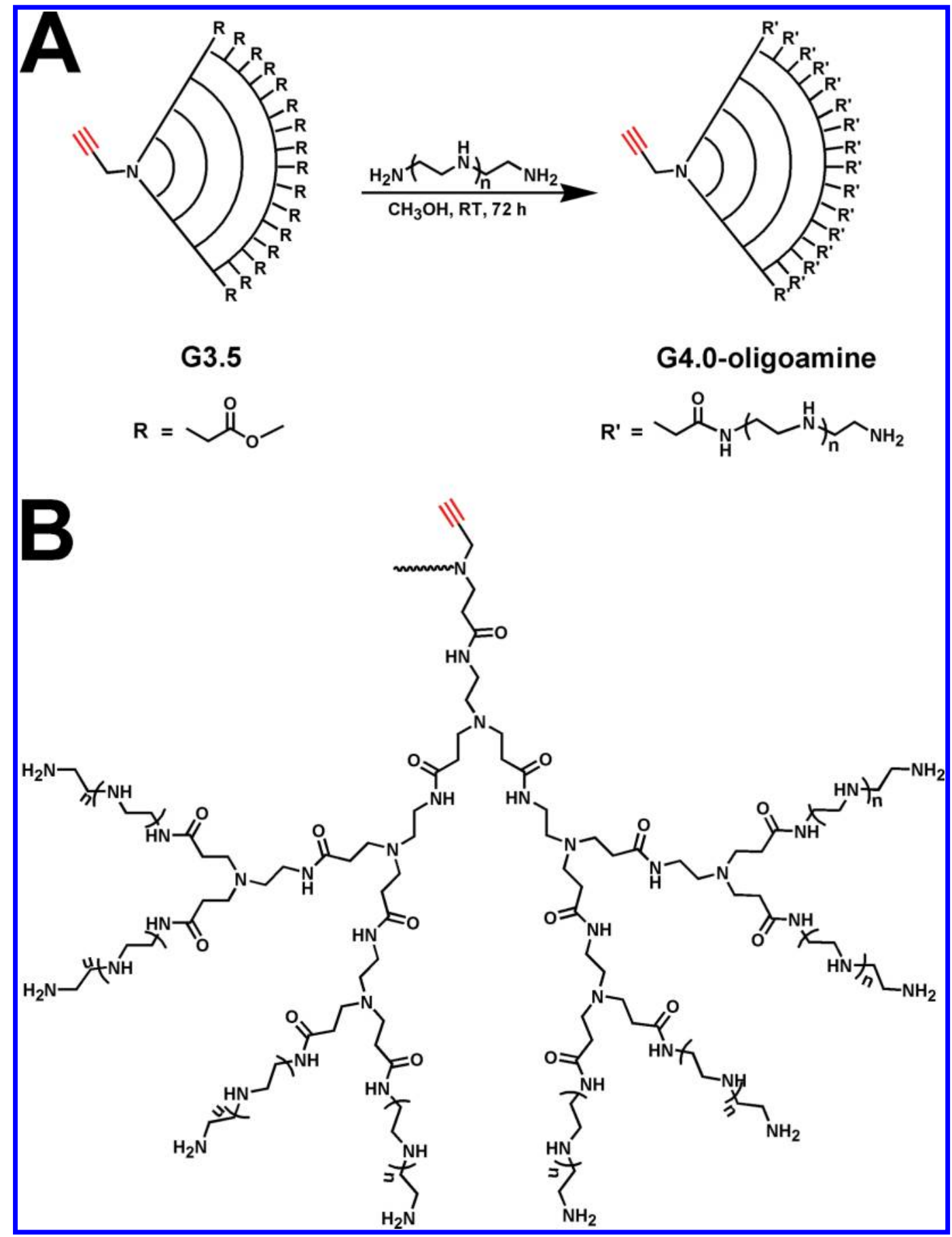

Figure 1. Oligoamine modification of propargyl-PAMAM dendron at chain termini. (A) Reaction scheme for terminal modification of PAMAM dendrons; (B) Representative chemical structure of oligoamine-modified G4.0 PAMAM dendrons $(n=0$, DEA; $n=1$, DETA; $n=2$, TETA; $n=3$, TEPA; $n=4$, PEHA).

buffer (20 mM Hepes buffer with 5\% (wt/v) glucose addition, $\mathrm{pH} 7.4)$ was used for polyplex preparation.

Particle Size and Zeta-Potential. The particle size and zetapotential of the prepared polyplexes in HBG were measured by Zetasizer Nano ZS (Malvern Instruments, Herrenberg, Germany) equipped with a $4 \mathrm{~mW} \mathrm{He}-\mathrm{Ne}$ laser at a wavelength of $633 \mathrm{~nm}$ at $25^{\circ} \mathrm{C}$. Zeta-potential measurement was performed in a folded capillary cell (Malvern Instruments, Herrenberg, Germany). The presented data were means out of three independent measurements.

Cell Culture. Neuro2A neuroblastoma cells (ATCC CCl-131) were purchased from DSMZ (Braunschweig, Germany). B16-F10 murine melanoma cells were kindly provided by Texas Medical Center (Houston, TX, U.S.A.). Both Neuro2A and B16-F10 cells were cultured in DMEM $\left(1.0 \mathrm{~g} \cdot \mathrm{L}^{-1}\right.$ glucose $)$ supplemented with $10 \% \mathrm{FCS}, 100 \mathrm{U} \cdot \mathrm{mL}^{-1}$ penicillin and $100 \mu \mathrm{g} \cdot \mathrm{mL}^{-1}$ streptomycin. HuH-7 hepatocellular carcinoma cells (JCRB 0403, Tokyo, Japan) were cultured in DMEM/HAM F-12 (1:1) medium containing $10 \% \mathrm{FCS}, 100 \mathrm{U} \cdot \mathrm{mL}^{-1}$ penicillin and $100 \mu \mathrm{g} \cdot \mathrm{mL}^{-1}$ streptomycin as described in our previous study. ${ }^{25}$ All the cells were cultured in $37^{\circ} \mathrm{C}$ incubator with $5 \% \mathrm{CO}_{2}$ supply and humidified atmosphere.

Cytotoxicity Assay. The metabolic activity of the cells incubated with polymer solutions was determined by MTT assay. B16-F10 cells were seeded in 96-well tissue culture plates (TPP, Transdingen, Switzerland) 
at a density of 5000 cells per well in $100 \mu \mathrm{L}$ of cell culture medium. Polymer solutions at different final concentrations were added when cells reached $60-80 \%$ confluence. The cell culture medium was replaced directly after $4 \mathrm{~h}$ polymer incubation. MTT solution $(10 \mu \mathrm{L}$ per well, $5.0 \mathrm{mg} \cdot \mathrm{mL}^{-1}$ in phosphate-buffered saline buffer, $\mathrm{pH}$ 7.4) was added $24 \mathrm{~h}$ later. The medium was replaced by $100 \mu \mathrm{L}$ of DMSO after $2 \mathrm{~h}$ MTT incubation. The optical absorbance was measured at $590 \mathrm{~nm}$ (reference wavelength $630 \mathrm{~nm}$ ) by a microplate reader (Spectraflour Plus, Tecan Austria GmbH, Austria). ${ }^{42}$ The metabolic activity of the polymer-treated cells was expressed as relative cell viability compared to that of untreated cell control.

Gene Transfer In Vitro. The gene transfer study in vitro was done in 96-well tissue culture plates. In a typical transfection experiment, B16-F10 cells were seeded at a density of 5000 cells per well, HuH-7 and Neuro2A cells were both seeded at a density of 10000 cells per well, respectively. A total of $24 \mathrm{~h}$ later after cell seeding, $20 \mu \mathrm{L}$ of polyplex solution containing $200 \mathrm{ng}$ of pDNA was added. The cell culture medium was changed after $4 \mathrm{~h}$ polyplex incubation. The luciferase activity of the polyplex treated cells was measured $24 \mathrm{~h}$ later after polyplex addition with a luminometer (Lumat LB 9507, Berchtold, Germany) as described previously. ${ }^{43}$ All transfection operations were done in five replicates. LPEI and BPEI polyplexes were prepared at polymer to pDNA weight ratio of 0.8 for all three different cell lines. ${ }^{44}$

EGFR overexpressing HuH-7 cells and control cell line Neuro2A (low in EGFR) were selected for targeted transfection studies. The EGF incorporated (EGF $(+)$ ) PEI polyplexes were prepared in optimized formulation and applied as positive controls: EGF-PEG10k-LPEI22/ 3PEG-LPEI22/BPEI25 = 13/22/100. The EGF free (EGF (-)) PEI polyplex controls were prepared in composition of 3PEG-LPEI22/ BPEI25 = 25/100 (same PEG ratio). ${ }^{34}$ Two EGF contents ( $5 \%$ and $10 \%)$ were selected to optimize the transfection condition of EGF incorporated PAMAM polyplexes.

\section{RESULTS AND DISCUSSION}

Synthesis and Chemo-Physical Characterization of PAMAM Dendrons. To synthesize oligoamine-modified PAMAM dendrons as demonstrated in Figure 1, PAMAM dendron in generation 3.5 with propargyl amine core and ester ends was first prepared by following the literature method. ${ }^{46}$ The chemical structure and molecular weights of the prepared propargylPAMAM dendrons were examined by ${ }^{1} \mathrm{H}$ NMR spectra (Figures SI 1 and SI 2) and mass spectra (Table SI 1), respectively. The molecular weights of propargyl-PAMAM dendrons determined by mass spectra were inconsistent with their theoretical molecular weights, indicating the successful synthesis of designed propargylPAMAM dendrons. The terminal ester groups of PAMAM dendron were then substituted by different oligoamines (DEA, DETA, TETA, TEPA, and PEHA; see Figure 1). The chemical compositions and corresponding substitution degrees of oligoaminemodified PAMAM dendrons were examined by ${ }^{1} \mathrm{H}$ NMR spectra. As shown in Figure 2A and Figure SI 1, the ${ }^{1} \mathrm{H}$ NMR peak around $3.6 \mathrm{ppm}$ disappeared, indicating the complete substitution of the ester groups. The oligoamine substitution degrees were determined by ${ }^{1} \mathrm{H}$ NMR spectra and the results were collected in Table 1. A substitution degree of $99 \%$ was found in DEA-modified dendron. The substitution degrees decreased when the oligoamine chain lengths were extended. This might be caused by the loop formation during the amidation reaction. ${ }^{46}$ The molecular weights $\left(M_{\mathrm{w}}\right.$ and $\left.M_{\mathrm{n}}\right)$ of oligoamine-modified PAMAM dendrons were measured by GPC examination. The molecular weights of PAMAM dendrons increased when modified with DEA, DETA, or TETA, but decreased when modified with TEPA or PEHA

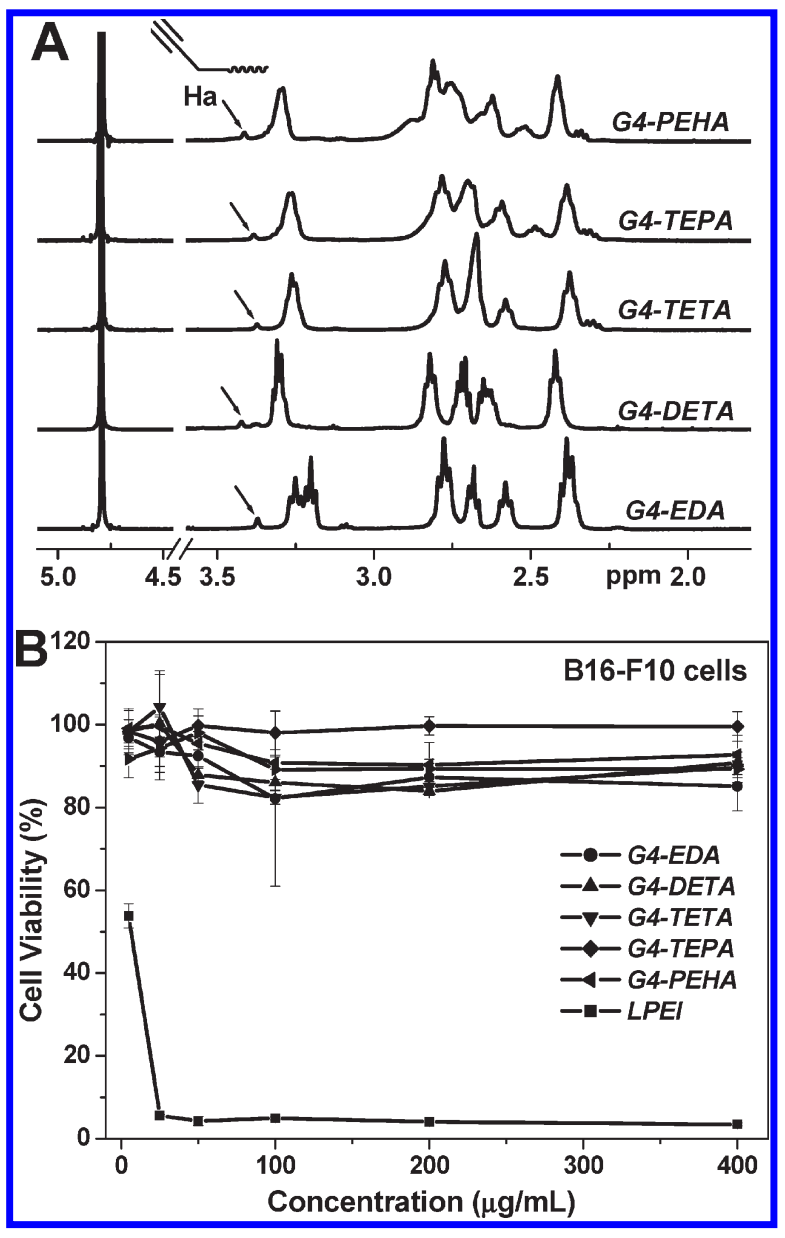

Figure 2. ${ }^{1} \mathrm{H}$ NMR spectra characterization and cytotoxicity assay for oligoamine-modified PAMAM dendrons. (A) ${ }^{1} \mathrm{H}$ NMR spectra of terminalmodified PAMAM dendrons; (B) Cytotoxicity assay for oligoaminemodified PAMAM dendrons in B16-F10 cells. The arrows indicated the presence of the propargyl group in the modified PAMAM dendrons. The cells kept metabolic activity over $90 \%$, suggesting the low cytotoxicity of oligoamine-modified G4 PAMAM dendrons.

compared with that of EDA ended one (see Table 1). This was most likely attributed to the condensed topological structure of PAMAM dendrons with longer oligoamine terminal chains. ${ }^{47}$ The molecular weight polydispersity (PDI) of DETA-, TETA-, TEPA-, or PEHAmodified PAMAM dendron became broader compared to that of PAMAM-EDA or PAMAM-DEA dendron, indicating the occurrence of intermolecular cross-linking during the amidation process. The termini secondary amino densities were calculated according to the ${ }^{1} \mathrm{H}$ NMR spectra determined substitution degrees. As shown in Table 1, the number of secondary amino groups increased when oligoamine chain was elongated. This correlated with the secondary amine density in each oligoamine chain.

The cytotoxicity of the surface-modified PAMAM dendrons in B16-F10 cells was examined by MTT assay. The cells treated by LPEI lost $90 \%$ of their metabolic activity at a polymer concentration of $25 \mu \mathrm{g} \cdot \mathrm{mL}^{-1}$. The PAMAM dendron treated cells kept more than $80 \%$ of their metabolic activity at polymer concentration of $400 \mu \mathrm{g} \cdot \mathrm{mL}^{-1}$. No significant difference was found among different oligoamine-modified PAMAM dendrons (see Figure 2B). This suggested that terminal modification of PAMAM dendron with different oligoamines did not enhance cytotoxicity of PAMAM 
Table 1. Molecular Parameters of Oligoamine-Modified G4 PAMAM Dendrons

$\begin{array}{ccccccc}\text { samples } & \operatorname{sub}^{a}(\%) & \text { theoretical } M_{\mathrm{w}}{ }^{b}\left(\times 10^{3}\right) & \text { determined } M_{\mathrm{w}}{ }^{c}\left(\times 10^{3}\right) & \text { determined } M_{\mathrm{n}}{ }^{c}\left(\times 10^{3}\right) & \text { PDI }\left(M_{\mathrm{w}} / M_{\mathrm{n}}\right) & \text { secondary amino groups }^{d} \\ \text { G4-EDA } & 99 & 3.48 & 6.27 & 3.46 & 1.81 & 0 \\ \text { G4-DETA } & 86 & 4.17 & 5.21 & 4.00 & 1.30 & 14 \\ \text { G4-TETA } & 84 & 4.86 & 8.94 & 4.05 & 2.20 & 27 \\ \text { G4-TEPA } & 82 & 5.55 & 7.46 & 4.93 & 1.51 & 39 \\ \text { G4-PEHA } & 71 & 6.24 & 5.92 & 4.67 & 1.27\end{array}$

${ }^{a} \mathrm{Sub}=$ degree of substitution (oligoamine units/16), calculated from ${ }^{1} \mathrm{H}$ NMR integration; ${ }^{b} M_{\mathrm{w}}$ was calculated with $100 \%$ substitution degree. ${ }^{c} M_{\mathrm{w}}$ and $M_{\mathrm{n}}$ were determined by GPC measurement. ${ }^{d}$ Number of secondary amino groups, calculated from integration of ${ }^{1} \mathrm{H}$ NMR peak area.
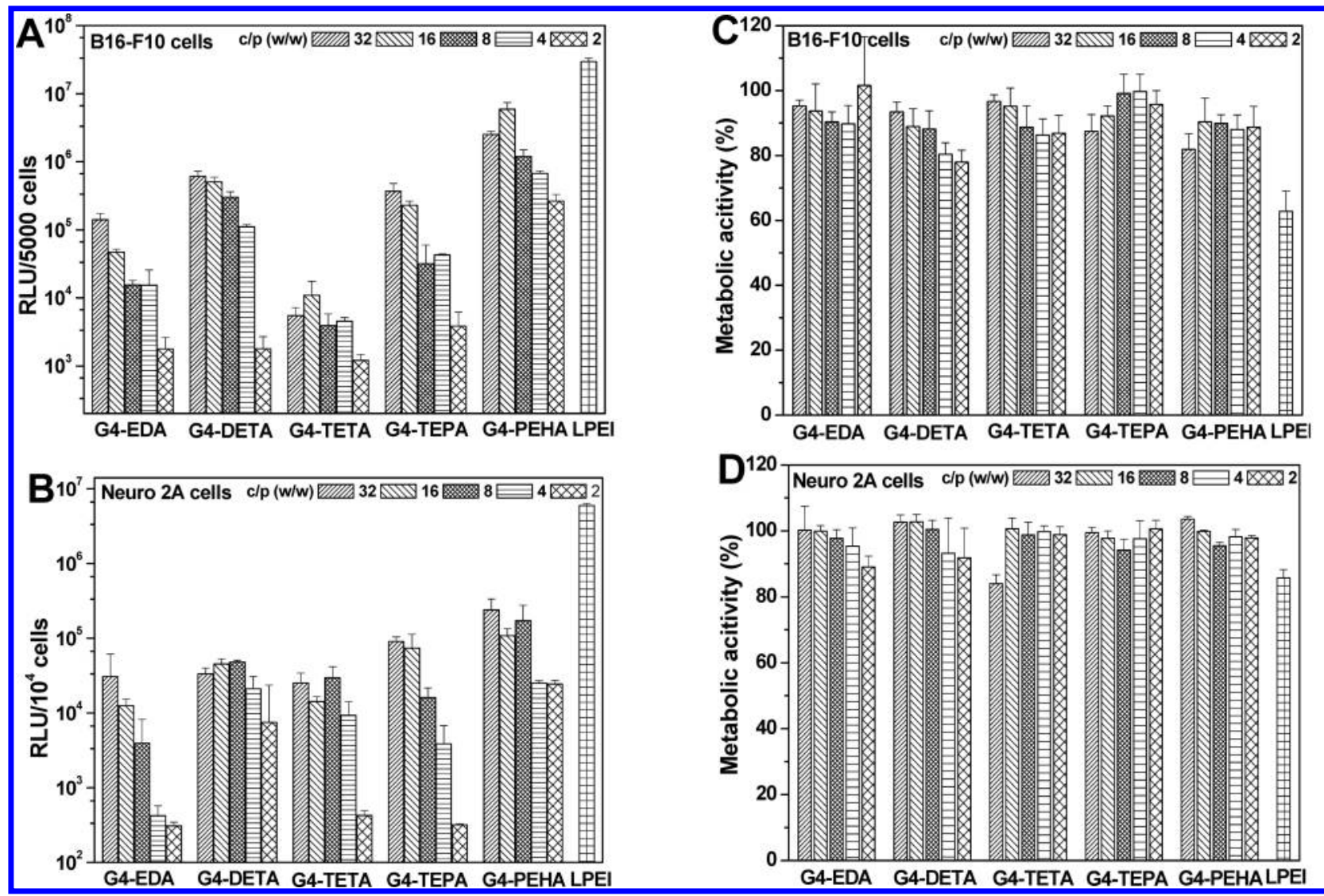

Figure 3. Luciferase activity and metabolic activity of B16-F10 (A, C) and Neuro2A cells (B, D) treated by oligoamine-modified PAMAM dendron polyplexes. The polyplexes were prepared in HBG buffer, and $200 \mathrm{ng}$ of pDNA per well was applied for 96-well tissue culture plate. The cell culture medium was changed $4 \mathrm{~h}$ after polyplex addition. The relative luciferase activity and metabolic activity of polyplexes treated cells were measured $24 \mathrm{~h}$ later. Presented data showed the average readout of five replicates $\left(n=5,{ }^{*} p<0.01\right)$.

dendrimers. The transfection property of PAMAM dendrons was examined in both $\mathrm{B} 16-\mathrm{F} 10$ and Neuro2A cells. As shown in Figure 3A,B, at different polymer to pDNA weight ratios, all modified PAMAM dendron polyplexes transfer pDNA efficiently into both cell lines. The B16-F10 and Neuro2A cells treated by the PAMAM polyplexes both showed metabolic activity higher than 90\% (see Figure 3C,D), suggesting that PAMAM polyplexes with different oligoamine modification induced noncytotoxic effects in transfected cells. At a defined polymer to pDNA weight ratio, PAMAM-PEHA polyplexes displayed the highest transfection efficiency in both B16-F10 and Neuro2A cells. We took it as the optimal composition for the next step of EGF-PEG functionalization.

EGF-PEG Functionalization of PAMAM-PEHA Dendron. Up to date, in reported literature on PEG-PAMAM linear-dendritic architectural copolymers, they were synthesized either by growing PAMAM dendron from the amino end of PEG chain ${ }^{48,49}$ or by grafting PEG chain onto PAMAM chain termini with NHS ester. ${ }^{50}$ However, the latter resulted in conjugations at random sites. In this study, we aimed to develop site-specific EGF-PEG functionalized PAMAM-PEHA conjugate for targeted gene delivery. To do that, PEG-PAMAM copolymer needed to be prepared first. $\mathrm{Cu}(\mathrm{I})$-catalyzed Huisgen $[2+3]$ dipolar cycloaddition reaction or so-called "click chemistry" is of high conversion rate and specificity. ${ }^{51}$ Thus, we applied click reaction to prepare PEG-PAMAM-PEHA copolymer. Because the click reaction had to be performed before the oligoamine coupling (because the polyamines were found to be incompatible with efficient click chemistry, our unpublished results), the synthesis procedure was optimized and shown in Figure 4. First, the azido group was coupled onto one end of PEG chain by reacting of 


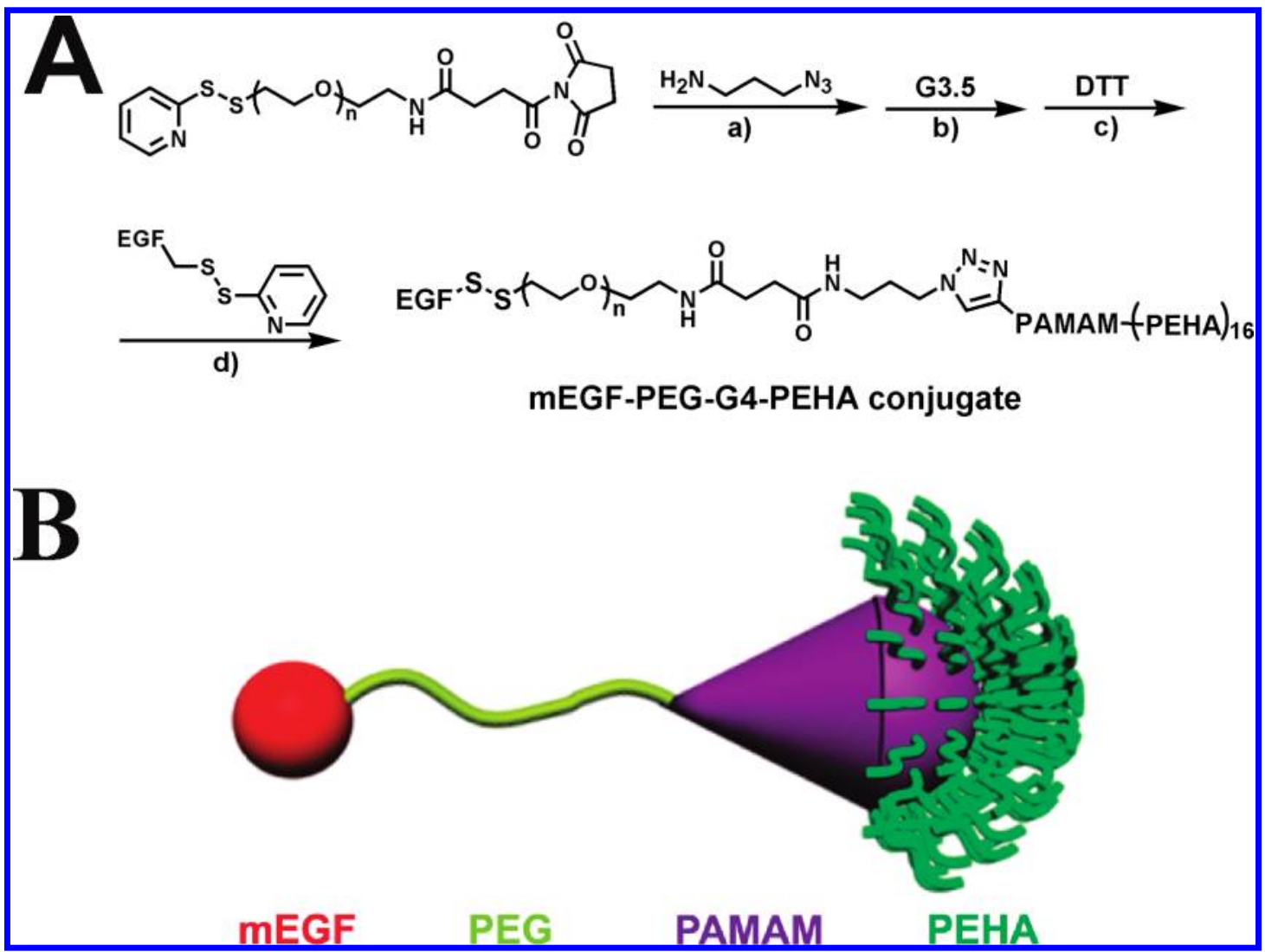

Figure 4. Design and synthesis of EGF functionalized PEG-PAMAM-PEHA conjugate. (A) Synthesis of EGF-PEG functionalized PAMAM-PEHA dendron via click chemistry: (a) anhydrous DMF, RT, 24 h; (b) ethanol, $\mathrm{CuBr} / \mathrm{Cu} / \mathrm{PMDETA}, 40^{\circ} \mathrm{C}, 24 \mathrm{~h}$; (c) DTT, $20 \mathrm{mM}$ Hepes buffer (pH 7.4), $24 \mathrm{~h}$; (d) 30\% ethanol-Hepes buffer (20 mM, pH 7.4), RT, 24 h. (B) Proposed structure of the EGF-PEG-PAMAM-PEHA conjugate. The PEHAmodified PAMAM dendron was taken as the optimal for PEG conjugation and EGF functionalization.

ester NHS with 1-azido-3-aminopropane, and then the PEG chain was conjugated with ester group ended PAMAM dendron through click reaction between azido and propargyl groups. For conversion into the EGF-PEG-PAMAM-PEHA conjugate, the resultant PEG-PAMAM linear-dendron architectural copolymer was aminolyzed with PEHA and further conjugated with EGF (mEGF) ligand. Our previous studies on EGF-PEG-PEI conjugates showed that PEG spacer with relatively low molecular weight $\left(M_{\mathrm{n}} 2 \mathrm{kDa}\right)$ was sufficiently high to shield PEI-based pDNA polyplexes and obtain an EGF receptor specific effect. Higher molecular weight PEG $\left(M_{\mathrm{n}} 5 \mathrm{kDa}\right)$ strongly reduced transfection activity of EGF-PEG-PEI polyplexes. ${ }^{34,36}$ Therefore, we used PDP-PEG-NHS $\left(M_{\mathrm{n}} 2 \mathrm{kDa}\right)$ to prepare the EGF-PEG-PAMAMPEHA conjugate.

The chemical structures of the intermediate products, such as PDP-PEG-azide and PDP-PEG-PAMAM-PEHA were characterized by ${ }^{1} \mathrm{H}$ NMR spectra examination (see Figures SI 5 and SI 6). The occurrence of the click reaction was confirmed by the presence of the proton signal assigned to the trizole group. For EGF coupling, thiol group on PEG spacer of PDP-PEG-PAMAMPEHA conjugate was first released by DTT treatment, EGF ligand was then covalently coupled to PEG spacer via a disulfide bond bridge. The thiol group concentration after DTT reduction was determined to be $1.15 \mathrm{mM}$ per gram of polycation $\left(\mathrm{mM} \cdot \mathrm{g}^{-1}\right)$ by combined Ellman's test and TNBS assay. The calculated molecular weight of PEG-PAMAM-PEHA conjugate was 8235.20 $\mathrm{Da}$ (the theoretical molecular weight of PAMAM-PEHA dendron plus the molecular weight of PEG; see Table 1). Thus, we estimated that there was one thiol group on each PEG-PAMAMPEHA chain. The EGF coupling reaction was monitored by determining the concentration of 2-pyridinethione produced during the reaction $\left(\mathrm{UV}_{\mathrm{abs}} 344 \mathrm{~nm}\right) .^{52}$ As shown in Figure SI 7 , the determined conversion percentages matched the theoretical ones well at four different EGF-PDP to copolymer feeding ratios, indicating the high conjugation efficiency between HSPEG-PAMAM-PEHA and mEGF-PDP. To prepare the final EGF-PEG-PAMAM-PEHA conjugate, 1.5-fold excess of mEGFPDP over copolymer was applied in the conjugation. The unreacted $\mathrm{mEGF}-\mathrm{PDP}$ was removed by cation-exchange chromatography to obtain purified mEGF-PEG-PAMAM-PEHA conjugate.

EGFR-EGF Interaction Mediated Targeted Gene Delivery. EGF ligand modification improved the transfection efficiency of PEI polyplexes by $10-100$ folds due to the accelerated internalization of polyplexes via EGFR-EGF interaction. ${ }^{32,33}$ To evaluate the influence of EGF conjugation on the gene transfer property of chain terminal modified PEG-PAMAM dendron, the transfection study was conducted in EGFR overexpressed $\mathrm{HuH}$ 7 cells (as shown in Figure 5A). With the optimized polyplex formulation, the EGF conjugated BPEI polyplexes displayed 12.6-fold higher luciferase activity than that of the EGF-free ones, being in good agreement with our previous observations. ${ }^{34}$ In the case of PAMAM polyplexes, two polyplex compositions and three different polymer to pDNA weight ratios were tested (see Figure SI 8). At the optimized polymer to pDNA weight ratio of 16 (polyplex composition: PAMAM/PEG-PAMAM/ EGF-PEG-PAMAM = 5/15/80), the HuH-7 cells treated by 


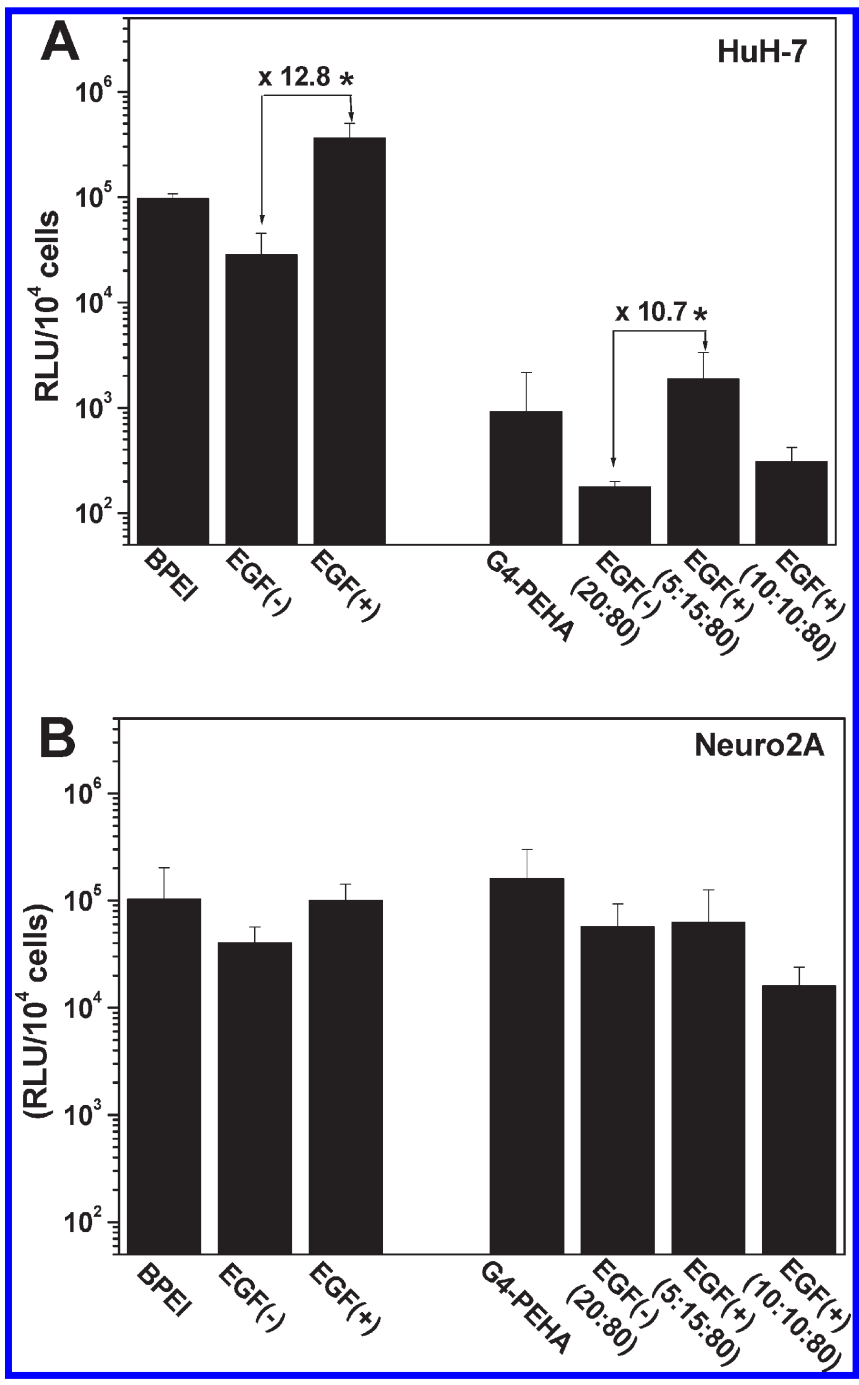

Figure 5. pDNA transfection study of EGF-PEG-PAMAM-PEHA polyplexes in (A) HuH-7 and (B) Neuro2A cells. At optimized polyplex composition (EGF-PEG-PAMAM-PEHA/PEG-PAMAM-PEHA/ PAMAM-PEHA $=5 / 15 / 80$, polymer to $\mathrm{pDNA}$ weight ratio of 16 ), 10-fold higher luciferase protein expression was detected in $\mathrm{HuH}-7$ cells compared to that of EGF free ones. EGF $(+)$ : polyplexes with PEG shielding and EGF conjugation; EGF(-): polyplexes with PEG shielding only $\left(n=5,{ }^{*} p<0.01\right)$.

EGF $(+)$ PAMAM polyplexes showed 10-fold enhancement of luciferase activity as compared to that treated by EGF(-) ones. We also examined the transfection efficiency of PAMAM polyplexes with higher PEG-PAMAM percentage of $25 \%$; only 1.5 fold higher luciferase expression was found compared to its parental PEG-PAMAM polyplexes, which might be due to the increased shielding effect on the polyplex surface with higher PEG density. To clarify the contribution of EGF-EGFR interaction on the improved gene transfer efficiency of PAMAM polyplexes, Neuro2A cells with low EGFR expression was selected as negative control. As shown in Figure 5B, Neuro2A cells treated with PEG shielded polyplexes with or without EGF coupling expressed equal or less luciferase protein compared to those treated with parental PAMAM polyplexes. This was most likely caused by the stable PEGylation, which had been demonstrated in our previous study to negatively affect endosomal escape. ${ }^{25,53}$
To elucidate the influence of polyplex particle size and surface charge on the gene transfer ability of EGF conjugated PAMAM polyplexes, the particle size and zeta-potential of the polyplexes prepared at the optimized compositions were measured (see Figure SI 9). BPEI polyplexes with or without EGF coupling all showed similar particle size around $100 \mathrm{~nm}$ due to the strong pDNA binding and compressing ability of BPEI. The particle size of PAMAM polyplexes was about $200 \mathrm{~nm}$. The particle size increased up to $340 \mathrm{~nm}$ with $10 \%$ PEG conjugation and 10\% EGF coupling, which might be caused by the reduced pDNA compressing ability of PAMAM polyplexes after PEG and EGF incorporation. The surface charge of BPEI polyplexes was reduced by PEG conjugation. The PAMAM polyplexes lost half of their surface positive charge by incorporating $20 \%$ of PEG-PAMAMPEHA (from +15 to $+8 \mathrm{mV}$ ). The surface charge of $10 \%$ EGF conjugated PEG-PAMAM-PEHA polyplexes was around + $10 \mathrm{mV}$. Considering that EGF(+) PAMAM polyplexes treated EGFR-low Neuro2A cells produce a comparable or lower transfection yield compared to that treated by EGF(-) one, the slight difference in surface charge was unlikely to cause the higher luciferase activity of EGF-PEG polyplexes transfected $\mathrm{HuH}-7$ cells. Together with the transfection data shown in Figure 2A, the improved transfection yield of $\operatorname{EGF}(+)$ polyplexes over that of EGF(-) ones in HuH-7 cells most likely is caused by the EGFEGFR interaction.

The main aim of this study, applying click chemistry for sitespecific conjugation of ligand-PEG to a PAMAM-PEHA conjugate for targeted gene delivery, was demonstrated and confirmed by the transfection data. However, the overall transfection efficiency was not as high enough as we expected for successful application. One of the possible pitfalls of the concept might be sterical inaccessibility of the EGF targeting ligand for EGFR. The applied mEGF is slightly acidic (isoelectric point around 5) and not basic; therefore, interaction with pDNA can be ruled out at physiological condition. In theory, EGF might interact with the cationized PAMAM polymer. However, as analogous EGF conjugates with various (linear and branched) types of polycationic PEI had been successfully applied before (see Figure 5A and literature), this should not result in major problems with targeting. Moreover, attachment of EGF ligand to PAMAMPEHA dendron with a PEG spacer should prevent it being buried in the core of polyplexes.

Notably, the EGF-PEG-PAMAM-PEHA polyplexes produced lower transfection rates in $\mathrm{HuH}-7$ cells than in Neuro2A cells in general, indicating the largest bottleneck in the pDNA delivery process was not in cell binding (with or without EGFR mediation) but in a subsequent intracellular delivery step, such as endosomal escape or nuclear transport. ${ }^{31}$ The situation might even be more complex for targeted gene delivery in vivo. The polyplexes with suitable particle size had to first accumulate in tumor site, usually passively via enhanced penetration and retention (EPR) effect. ${ }^{54}$ In related work, ligands had not significantly altered tumor accumulation but intracellular uptake and activity. ${ }^{55}$ The EGF-EGFR interaction would be expected to locally improve the internalization of polyplexes. ${ }^{31}$

In sum, further modifications have to be made for overcoming subsequent gene delivery steps after receptor-mediated targeted cell binding. Bioreversible PEGylation might be one possible solution. ${ }^{25,33}$ PAMAM dendrimer in higher generations usually generate improved transfection yield via enhanced endosome escape capacity. ${ }^{20}$ Alternatively, the transfection efficiency of our developed EGF-PEG-PAMAM-PEHA polyplexes could possibly 
be improved by selecting PAMAM dendrons with higher generations than that applied in current study, with the PEG shielding preventing enhanced cytotoxicity.

\section{CONCLUSION}

In this study, a novel synthetic strategy via click chemistry was developed for site-specific EGF-PEG functionalization of PAMAM dendron. The impact of chain terminal modification on the transfection properties of PAMAM dendrons was investigated. The oligoamines with higher secondary amino group densities resulted in higher gene transfer efficiency, which might attribute to the improved proton sponge capacity. The PAMAMPEHA dendron structure was selected as basis for incorporation of EGF-PEG via click chemistry. Click chemistry had to be performed before PEHA incorporation. The EGF-PEG functionalized PAMAM-PEHA dendron polyplexes displayed selectively improved gene transfer ability in EGFR overexpressing HuH-7 cells. Further modifications will be required to optimize the transfection efficiency of the EGF functionalized PAMAM polyplexes.

\section{ASSOCIATED CONTENT}

S Supporting Information. The experimental detail for propargyl-PAMAM dendron synthesis, ${ }^{1} \mathrm{H}$ NMR spectra, polyplex particle size, and zeta potential data. This material is available free of charge via the Internet at http://pubs.acs.org.

\section{AUTHOR INFORMATION}

\section{Corresponding Author}

*E-mail: haijun.yu@wpi-aimr.tohuko.ac.jp.

\section{Present Addresses}

${ }^{\dagger}$ WPI-Advanced Institute of Materials Research, Tohoku University, Sendai 980-8577, Japan.

${ }^{\ddagger}$ National Engineering Research Center for Biomaterials, Sichuan University, Chengdu, 610064, Sichuan, P. R. China.

${ }^{\S}$ Department of Chemistry and Biology, College of Science, National University of Defense Technology, Changsha, 410073, Hunan, P. R. China.

\section{ACKNOWLEDGMENT}

We thank the assistance of Wolfgang Roedl for HPLC purification of the copolymer. We acknowledge the financial support by DFG excellence cluster NIM and EC project GIANT, the Alexander von Humboldt fellowship to Y.N., and the CSC visiting fellowships to Y.L.

\section{REFERENCES}

(1) Davis, M. E. Curr. Opin. Biotechnol. 2002, 13, 128-131.

(2) Wagner, E.; Zenke, M.; Cotten, M.; Beug, H.; Birnstiel, M. L. Proc. Natl. Acad. Sci. U.S.A. 1990, 87, 3410-3414.

(3) Li, S. D.; Huang, L. I. Controlled Release 2007, 123, 181-183.

(4) Davis, M. E.; Zuckerman, J. E.; Choi, C. H. J.; Seligson, D.; Tolcher, A.; Alabi, C. A.; Yen, Y.; Heidel, J. D.; Ribas, A. Nature 2010, 464, 1067-1070.

(5) Simoes, S.; Filipe, A.; Faneca, H.; Mano, M.; Penacho, N.; Duzgunes, N.; de Lima, M. P. Expert Opin. Drug Delivery 2005, 2, 237254.

(6) Wagner, E.; Culmsee, C.; Boeckle, S. Adv. Genet. 2005, 53, 333354.
(7) Kataoka, K.; Itaka, K.; Nishiyama, N.; Yamasaki, Y.; Oishi, M.; Nagasaki, Y. Nucleic Acids Symp. Ser. 2005, 49, 17-28.

(8) Zhao, X.; Pan, F.; Zhang, Z.; Grant, C.; Ma, Y.; Armes, S. P.; Tang, Y.; Lewis, A. L.; Waigh, T.; Lu, J. R. Biomacromolecules 2007, 8, 3493-3502.

(9) Plank, C.; Mechtler, K.; Szoka, F. C., Jr.; Wagner, E. Hum. Gene Ther. 1996, 7, 1437-1446.

(10) Tomalia, D. A.; Hedstrand, D. M. Actual Chim. 1992, 5, $347-349$.

(11) Kannan, R. M.; Menjoge, A. R.; Tomalia, D. A. Drug Discovery Today 2010, 15, 171-185.

(12) Balogh, L.; de Leuze-Jallouli, A.; Dvornic, P.; Kunugi, Y.; Blumstein, A.; Tomalia, D. A. Macromolecules 1999, 32, 1036-1042.

(13) Svenson, S.; Tomalia, D. A. Adv. Drug Delivery Rev. 2005, 57, 2106-2129.

(14) Esfand, R.; Tomalia, D. A. Drug Discoverv Todav 2001, 6, 427436.

(15) Choi, J. S.; Nam, K.; Park, J.; Kim, J. B.; Lee, J. K.; Park, J. I. Controlled Release 2004, 99, 445-456.

(16) Yellepeddi, V. K.; Kumar, A.; Palakurthi, S. Exp. Opin. Drug Delivery 2009, 6, 835-850.

(17) Kloeckner, J.; Wagner, E.; Ogris, M. Eur. J. Pharm. Sci. 2006, 29, 414-425.

(18) Zou, S. M.; Erbacher, P.; Remy, J. S.; Behr, J. P. J. Gene Med. 2000, 2, 128-134.

(19) Boussif, O.; Lezoualch, F.; Zanta, M. A.; Mergny, M. D.; Scherman, D.; Demeneix, B.; Behr, J. P. Proc. Natl. Acad. Sci. U.S.A. 1995, 92, 7297-7301.

(20) Navarro, G.; Maiwald, G.; Haase, R.; Rogach, A. L.; Wagner, E.; de Ilarduya, C. T.; Ogris, M. J. Controlled Release 2010, 17, 99-105.

(21) Zhang, X. Q.; Wang, X. L.; Huang, S. W.; Zhuo, R. X.; Liu, Z. L.; Mao, H. Q.; Leong, K. W. Biomacromolecules 2005, 6, 341-350.

(22) Russ, V.; Frohlich, T.; Li, Y.; Halama, A.; Ogris, M.; Wagner, E. I. Gene Med. 2010, 12, 180-193.

(23) Kursa, M.; Walker, G. F.; Roessler, V.; Ogris, M.; Roedl, W.; Kircheis, R.; Wagner, E. Bioconiugate Chem. 2003, 14, 222-231.

(24) Yu, H.; Wagner, E. Curr. Opin. Mol. Ther. 2009, 11, 165-178.

(25) Walker, G. F.; Fella, C.; Pelisek, J.; Fahrmeir, J.; Boeckle, S.; Ogris, M.; Wagner, E. Mol. Ther. 2005, 11, 418-425.

(26) Meyer, M.; Wagner, E. Exp. Opin. Drug Delivery 2006, 3, 563571.

(27) Kircheis, R.; Kichler, A.; Wallner, G.; Kursa, M.; Ogris, M.; Felzmann, T.; Buchberger, M.; Wagner, E. Gene Ther. 1997, 4, 409-418.

(28) Ogris, M.; Wagner, E. Drug Discoverv Todav 2002, 7, 479-485.

(29) von Gersdorff, K.; Ogris, M.; Wagner, E. Eur. J. Pharm. Biopharm. 2005, 60, 279-285.

(30) Carlin, C. R.; Simon, D.; Mattison, J.; Knowles, B. B. Mol. Cell. Biol. 1988, 8, 25-34.

(31) de Bruin, K.; Ruthardt, N.; von Gersdorff, K.; Bausinger, R.; Wagner, E.; Ogris, M.; Brauchle, C. Mol. Ther. 2007, 15, 1297-1305.

(32) Kircheis, R.; Blessing, T.; Brunner, S.; Wightman, L.; Wagner, E. I. Controlled Release 2001, 72, 165-170.

(33) Blessing, T.; Kursa, M.; Holzhauser, R.; Kircheis, R.; Wagner, E. Bioconiugate Chem. 2001, 12, 529-537.

(34) Shir, A.; Ogris, M.; Wagner, E.; Levitzki, A. PLoS Med. 2006, 3, e6.

(35) Wolschek, M. F.; Thallinger, C.; Kursa, M.; Rossler, V.; Allen, M.; Lichtenberger, C.; Kircheis, R.; Lucas, T.; Willheim, M.; Reinisch, W.; Gangl, A.; Wagner, E.; Jansen, B. Hepatology 2002, 36, 11061114.

(36) Schaffert, D.; Kiss, M.; Rodl, W.; Shir, A.; Levitzki, A.; Ogris, M.; Wagner, E. Pharm. Res. 2010, 28, 731-741.

(37) Plank, C.; Zatloukal, K.; Cotten, M.; Mechtler, K.; Wagner, E. Bioconiugate Chem. 1992, 3, 533-539.

(38) Russ, V.; Elfberg, H.; Thoma, C.; Kloeckner, J.; Ogris, M.; Wagner, E. Gene Ther. 2008, 15, 18-29.

(39) Lee, J. W.; Kim, J. H.; Kim, H. J.; Han, S. C.; Shin, W. S.; Jin, S. H. Bioconiugate Chem. 2007, 18, 579-584. 
(40) Hua, C.; Peng, S. M.; Dong, C. M. Macromolecules 2008, 41, 6686-6695.

(41) Carboni, B.; Benalil, A.; Vaultier, M. J. Org. Chem. 1993, 58, 3736-3741.

(42) Yu, H.; Russ, V.; Wagner, E. AAPS I. 2009, 11, 445-455.

(43) Kloeckner, J.; Bruzzano, S.; Ogris, M.; Wagner, E. Bioconjugate Chem. 2006, 17, 1339-1345.

(44) Boeckle, S.; von Gersdorff, K.; van der Piepen, S.; Culmsee, C.; Wagner, E.; Ogris, M. L. Gene Med. 2004, 6, 1102-1111.

(45) Russ, V.; Gunther, M.; Halama, A.; Ogris, M.; Wagner, E. L. Controlled Release 2008, 132, 131-140.

(46) Tomalia, D. A.; Hedstrand, D. M.; Ferritto, M. S. Macromolecules 1991, 24, 1435-1438.

(47) Maiti, P. K.; Cagin, T.; Wang, G. F.; Goddard, W. A. Macromolecules 2004, 37, 6236-6254.

(48) Iyer, J.; Fleming, K.; Hammond, P. T. Macromolecules 1998, $31,8757-8765$.

(49) Wood, K. C.; Azarin, S. M.; Arap, W.; Pasqualini, R.; Langer, R.; Hammond, P. T. Bioconiugate Chem. 2008, 19, 403-405.

(50) Luo, D.; Haverstick, K.; Belcheva, N.; Han, E.; Saltzman, W. M. Macromolecules 2002, 35, 3456-3462.

(51) Lutz, J. F.; Zarafshani, Z. Adv. Drug Delivery Rev. 2008, 60, 958-970.

(52) Zugates, G. T.; Anderson, D. G.; Little, S. R.; Lawhorn, I. E.; Langer, R. I. Am. Chem. Soc. 2006, 128, 12726-12734.

(53) Nie, Y.; Günther, M.; Gu, Z.; Wagner, E. Biomaterials 2011, $32,858-869$.

(54) Maeda, H. Bioconiugate Chem. 2010, 21 (5), 797-802.

(55) Bartlett, D. W.; Su, H.; Hildebrandt, I. J.; Weber, W. A.; Davis, M. E. Proc. Natl. Acad. Sci. U.S.A. 2007, 104, 15549-15554. 